\title{
Pierre PARLEBAS (dir.), Jeux traditionnels, sports et patrimoine culturel. Cultures et éducation
}

Jean-Paul Callède

\section{(2) OpenEdition}

1 Journals

Édition électronique

URL : https://journals.openedition.org/ress/4083

DOI : $10.4000 /$ ress.4083

ISSN : 1663-4446

Éditeur

Librairie Droz

Édition imprimée

Date de publication : 14 décembre 2018

Pagination : 293-296

ISSN : 0048-8046

\section{Référence électronique}

Jean-Paul Callède, « Pierre PARLEBAS (dir.), Jeux traditionnels, sports et patrimoine culturel. Cultures et éducation », Revue européenne des sciences sociales [En ligne], 56-2 | 2018, mis en ligne le 14 décembre 2018, consulté le 07 janvier 2022. URL : http://journals.openedition.org/ress/4083 ; DOI : https:// doi.org/10.4000/ress.4083

Ce document a été généré automatiquement le 7 janvier 2022.

(c) Librairie Droz 


\title{
Pierre PARLEBAS (dir.), Jeux traditionnels, sports et patrimoine culturel. Cultures et éducation
}

\author{
Jean-Paul Callède
}

\section{RÉFÉRENCE}

Pierre PARLEBAS (dir.), 2016, Jeux traditionnels, sports et patrimoine culturel. Cultures et éducation, Paris, L'Harmattan, « Mouvement des savoirs », 310 p.

1 La courte préface du maître d'œuvre, Pierre Parlebas (p. 11-12), précise le défi auquel se confronte cette entreprise collective: "essayer de clarifier certains des grands problèmes transversaux » qui s'attachent au domaine des jeux et des sports, sans ignorer les tensions et conflits qui opposent «singularité locale du jeu» et "universalité mondiale du sport». Pour se démarquer des images et des discours convenus, il est impératif de faire appel à une grande rigueur conceptuelle et à une solide méthodologie d'enquête de terrain. Le livre rassemble une douzaine d'auteurs, « un large éventail de chercheurs» dont les contributions, soit 15 chapitres au total, puisent leur information dans différentes cultures, communautés et collectivités.

Rédigé par Pierre Parlebas lui-même et intitulé « Le jeu fait-il partie de la culture ? », le premier chapitre fixe les objectifs de l'ouvrage : baliser le domaine et apporter un sens précis qu'il est indispensable d'" attribuer aux termes jeu, sport et culture », dont l'usage polysémique fragilise toute objectivation scientifique. Alors que le sport permet d'identifier un vaste ensemble de pratiques culturelles marqué par une « uniformisation des comportements » et par un " processus de convergence », les jeux révèlent, au niveau local et "dans des creusets culturels originaux", "une ludodiversité exubérante» (p.32) qui fait surgir d'«innombrables et spectaculaires disparités » (p. 29). Ce patrimoine culturel est de première importance. Comprendre les jeux et les valeurs dont ils sont porteurs oblige à les replacer dans leur environnement 
historique et social. «Les jeux dogons, chinois, malgaches ou argentins », souligne l'auteur, traduisent « une ethnomotricité révélatrice des traits culturel saillants de leur communauté » (p. 33). « Le "je" de chaque ethnie s'exprime par ses jeux » (p. 34). Sur le Vieux Continent, ces activités bénéficient parfois d'une promotion associative (sociétés de jeu de boules, de quilles, etc.). En outre, des façons nouvelles de se réapproprier des sports constituent un domaine supplémentaire, à l'exemple des « jeux de rue » dont les groupes « secrètent une contre-acculturation ".

3 Les deux chapitres suivants s'emploient à caractériser des modèles de pratique spécifiques qui peuvent se trouver en situation de concurrence ou dans des rapports de force les uns par rapport aux autres. Pour Guy Jaouen (chap. 2), on doit distinguer trois ensembles spécifiques relatifs à la " culture corporelle »: le "sport », caractérisé par sa «supranationalité » et la «logique du marché, les «jeux traditionnels» qui relèvent d'une « logique de la société civile » et la « forme physique » qui répond à un impératif de "santé » porté par l'État » (voir schéma, p. 54). Bertrand During (chap. 3) propose une autre grille de lecture des modèles d'organisation des pratiques (voir schéma, p. 70) qui place le sport à l'intersection de deux axes : Agon (ascèse) vs Ludus (spectacle) et Jocus (fantaisie) vs Gymnastique (travail). Aujourd'hui, ces « pôles » sont actifs, nourris d'oppositions et d'interactions partielles. Et s'il est «difficile de dire lesquels sont l'avenir des autres, les jeux et les sports gagnent à être vécus et analysés ensemble plutôt qu'à être opposés » (p. 74).

4 Ce qui ressemble à une sorte de bilan d'étape dans l'ouvrage trouve un prolongement synthétique dans le chapitre 4 signé par Pierre Parlebas: «L'univers des jeux et des sports ». Il est indispensable de disposer d'une "organisation de l'ensemble des activités ludomotrices (voir schéma, p. 79) dans lequel les « sports » occupent une place précise dont les quatre traits distinctifs, à la fois nécessaires et suffisants, sont " situation motrice », « système de règles ", « compétition » et « institutionnalisation ». De même, ce que l'on appelle communément « jeux » recouvre une variété de situations qui prennent place dans le schéma mentionné et quelques autres.

5 Les trois chapitres qui suivent traitent de caractéristiques supplémentaires qui introduisent des éléments de complexité à propos du domaine : «Jeux d'enfants et jeux d'adultes » (Pere Lavega Burgués, chap. 5), «Violence et agressivité dans le jeu sportif » (Luc Collard, chap. 6) et «Jeux et rites chez les Indiens d'Amérique du Nord » (Fabrice Delsahut, chap. 7). Pierre Parlebas intervient à nouveau avec un chapitre de synthèse théorique intitulé "La logique interne des jeux sportifs : classification » (chap. 8). Une science de l'action motrice est désormais établie, dont l'auteur a su formaliser et théoriser l'ensemble des traits pertinents, qu'il n'est pas possible de reprendre ici dans le détail. Ces modélisations, leur traduction en données statistiques permettent une relecture scientifique des disciplines valorisées par les Jeux olympiques (y compris dans la course aux médailles), ou de revisiter des jeux en vigueur en Afrique, en Asie, etc., qui correspondent en partie, in fine, à une "distribution géopolitique sélective des pratiques ludomotrices » ébauchée dans l'article (p. 190).

6 Une permutation entre le chapitre sur les «jeux collectifs de rue» (Pascal Bordes, chap.9) et celui de Fabrice Delsahut permettrait de renforcer la dynamique d'exposition de l'ouvrage. Une fois traitée la « logique interne » des jeux et des sports, il convient de revenir sur la logique contextuelle, l'environnement culturel élargi qui entoure les jeux dans les sociétés traditionnelles. C'est ainsi que Fabrice Delsahut porte l'attention sur les rites préparatoires et les jeux rituels observés dans diverses sociétés 
des Indiens d'Amérique du Nord. L'objectif visé par Il Bong Paik et Gérard Fouquet est assez comparable : "Liens entre jeux et cultures : l'exemple de la Corée " (chap. 10). Outre les « caractéristiques internes des jeux », précisant « l'espace, les objets, le temps, les contacts corporels et les scores de ces jeux» (p. 221), les auteurs notent que ces formes concrètes n'ont de sens "que dans le cadre plus large d'un système de conventions plus ou moins contraignantes que lui confère le groupe social» (p. 227). Un peu comme en littérature, l'analyse du texte ne peut ignorer l'éclairage du contexte mais le contexte ne saurait rendre compte à lui seul des subtilités créatrices du texte.

7 Le chapitre 11, "Les universaux du jeu sportif», de Pierre Parlebas encore, vise à fournir des éléments de réponse à la question suivante : «Qu'apporte chaque jeu sportif et quels sont ses mécanismes de fonctionnement?» (p. 229). En explorant méthodiquement ces aspects, l'auteur expose les acquis de plusieurs décennies de travaux personnels. Cette méthode stimulante propose des supports immédiatement disponibles pour l'observation, le recueil et le traitement des données. "Grilles d'observation, graphes, matrices, ludogrammes, etc.» donnent des clefs d'analyse indispensables. D'un côté des jeux sportifs qui ont une puissance «à représenter les normes et les valeurs culturelles de leur société de référence ", sans oublier, de l'autre, " leur capacité à révéler les émotions, les prises de conscience et le vécu des joueurs " (p. 247). Le chapitre "Jeux sportifs avec bâtons et crosses", rédigé par Jacques Le Garlantézec (chap.13), en est une démonstration vivante, conduite à l'échelle des continents (voir carte p. 266).

8 Christophe Peter ouvre quant à lui une perspective inédite, peut-être une opportunité à saisir, en abordant le thème suivant: "Jeux traditionnels et jeux vidéo: vers une réappropriation digitale du patrimoine ludique mondial » (chap.12). On peut en dire autant du chapitre «La Charte de la Terre en action motrice », de Francisco Lagardera Otero (chap. 14). Cette «Charte» est tenue par l'UNESCO comme étant un instrument d'éducation doublé d'un cadre éthique majeur du développement durable. Dans la période de transition que connaît la planète, l'auteur fait l'hypothèse que la vie quotidienne des individus, et en particulier des jeunes générations, pourrait être enrichie d'une pratique raisonnée de certains jeux et de leurs conséquences (compétitions partageantes vs compétitions excluantes, par exemple).

Quelques pages de bilan et de conclusion sont proposées enfin par Pierre Parlebas (chap. 15). Il faut y ajouter des thèses et des intuitions fameuses ça et là rappelées. Conçues par Marcel Mauss, Johan Huizinga, Claude Lévi-Strauss, Roger Caillois, Norbert Elias, Allen Guttmann, etc., elles sont ponctuellement discutées. Mais l'apport majeur de cet ouvrage est ailleurs. La diffusion hégémonique du sport, qui opère à l'échelle planétaire grâce à des organismes tout puissants et argentés, est un des facteurs de menace qui pèse sur les jeux dits "traditionnels », témoins fragiles d'un patrimoine en danger. Plusieurs auteurs font ainsi référence au rôle de l'UNESCO, organisation au sein de laquelle certains d'entre eux ont apporté des éclairages importants. Pour autant, les appartenances institutionnelles des auteurs et leur statut combiné de chercheurs, d'éducateurs et de militants d'associations qui se fondent en partie sur la praxéologie motrice (les Centres d'entraînement aux méthodes d'éducation active, par exemple, ou la Fédération internationale des luttes celtiques) expliquent l'interrogation majeure qui structure l'ouvrage. "Jeux et sports peuvent-ils être insérés avec pertinence dans un programme d'éducation physique et devenir partie prenante du système éducatif ? " (Parlebas, p. 12). Si l'UNESCO vise à promouvoir le respect mutuel dans le cadre d'une 
diversité des cultures préservées, quelle montée en généralité peut être opérée, au titre d'une éducation physique de la jeunesse, à partir d'une connaissance dépassionnée et objective des jeux et des sports? Un patrimoine culturel ne vaut sans doute que par la compréhension interculturelle qu'il suppose, au moins potentiellement. Comment traduire cela dans des actes éducatifs ? Pour l'équipe rassemblée dans Jeux traditionnels, sports et patrimoine culturel, la praxéologie motrice permet d'atteindre un niveau de scientificité qui s'affranchit de la simple « juxtaposition de disciplines hétérogènes » et, plus encore, des risque idéologiques que sont la glorification ou la dépréciation de certaines activités ludomotrices. Ce livre, modestement qualifié d'«ouvrage de présentation » en ouverture (p.11), peut être lu à la fois comme une synthèse réussie des acquis du moment, au regard du titre et du sous-titre du volume, et comme un message d'avenir sur la nécessité de protéger et de faire fructifier cet héritage culturel mondial.

\section{AUTEURS}

JEAN-PAUL CALLÈDE

CNRS, GEMASS - Université Paris-IV 